Supplement of The Cryosphere, 14, 769-788, 2020 https://doi.org/10.5194/tc-14-769-2020-supplement (C) Author(s) 2020. This work is distributed under the Creative Commons Attribution 4.0 License.

(c) (1)

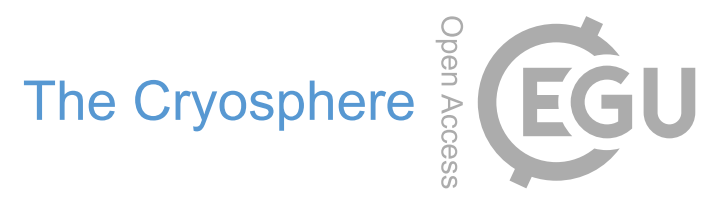

Supplement of

\title{
The seasonal evolution of albedo across glaciers and the surrounding landscape of Taylor Valley, Antarctica
}

\author{
Anna Bergstrom et al. \\ Correspondence to: Anna Bergstrom (anna.bergstrom@ colorado.edu)
}

The copyright of individual parts of the supplement might differ from the CC BY 4.0 License. 
Table S1. Total number of reflected radiation measurements taken over each of the three main glaciers and lakes and E. and W. valley soils across all flights.

15-16

16-17

17-18

\begin{tabular}{|c|c|c|c|c|c|c|c|c|c|c|c|c|c|c|}
\hline & 20-Nov & 7-Dec & 24-Dec & 5-Jan & 12-Jan & 11-Nov & 3-Dec & 27-Dec & 3-Jan & 23-Jan & 22-Nov & 7-Dec & 27-Dec & 13-Jan \\
\hline Taylor Gl. & 173 & 172 & 70 & 157 & 95 & 110 & 98 & 0 & 84 & 82 & 119 & 105 & 232 & 113 \\
\hline Canada Gl. & 74 & 49 & 83 & 76 & 89 & 85 & 67 & 128 & 73 & 68 & 184 & 89 & 84 & 91 \\
\hline Comwlth G1. & 72 & 74 & 60 & 76 & 69 & 83 & 57 & 72 & 53 & 60 & 98 & 97 & 77 & 100 \\
\hline L. Bonney & 114 & 16 & 64 & 105 & 114 & 156 & 44 & 61 & 86 & 81 & 156 & 157 & 110 & 154 \\
\hline L. Hoare & 61 & 12 & 51 & 32 & 51 & 83 & 37 & 50 & 59 & 47 & 84 & 72 & 38 & 64 \\
\hline L. Fryxell & 103 & 28 & 91 & 52 & 97 & 119 & 45 & 98 & 88 & 84 & 114 & 113 & 92 & 113 \\
\hline W valley soil & 134 & 202 & 114 & 181 & 199 & 115 & 127 & 105 & 102 & 88 & 115 & 119 & 113 & 123 \\
\hline E valley soil & 57 & 67 & 33 & 51 & 60 & 43 & 120 & 50 & 54 & 60 & 39 & 39 & 48 & 36 \\
\hline
\end{tabular}



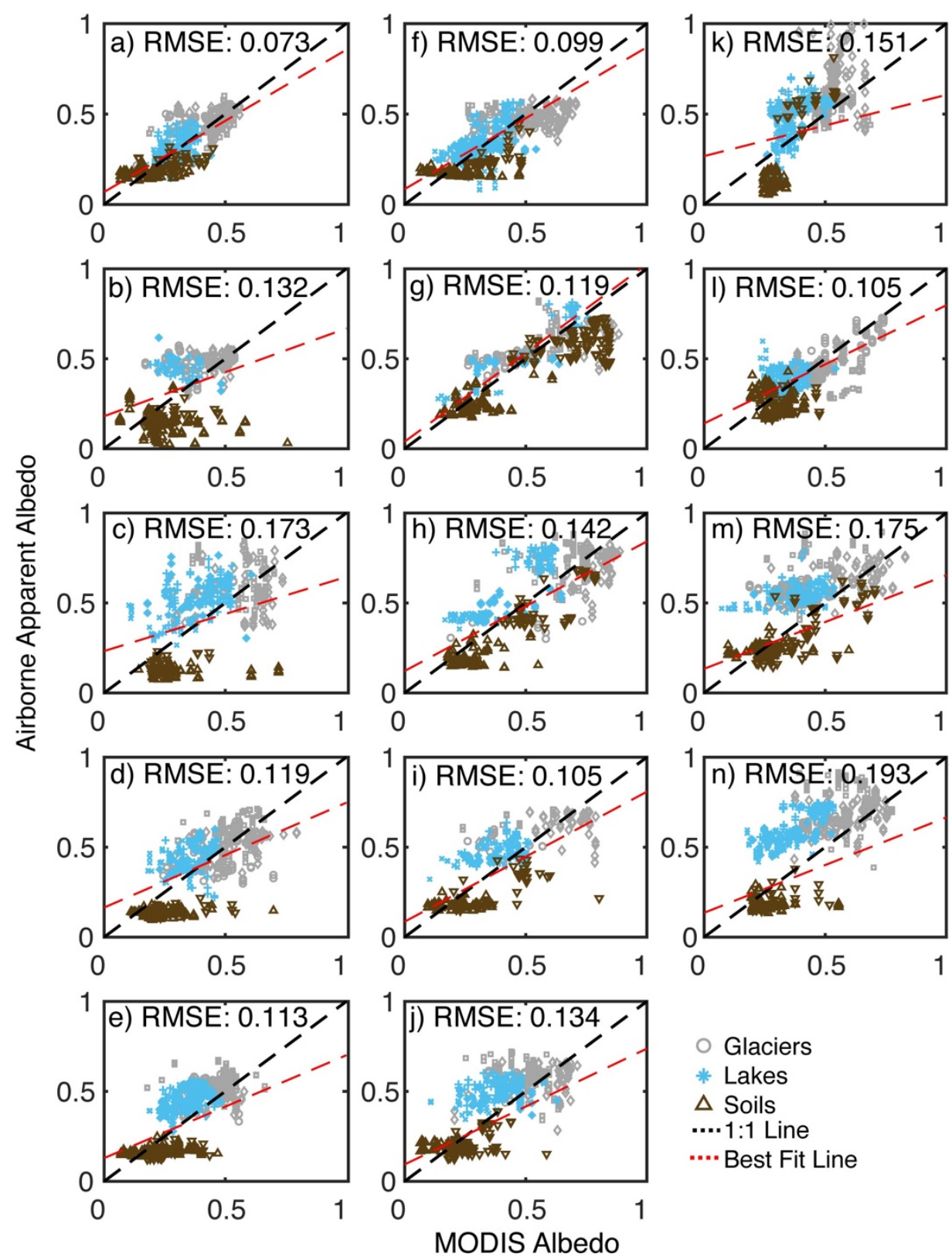

- Glaciers

* Lakes

$\Delta$ Soils

....1:1 Line

... Best Fit Line

Figure S1: Comparison of apparent (uncorrected) albedo to MODIS data across each flight in the (a-e) 2015-16 (f-j) 2016-17 and (k-n) 2017-18 seasons. 

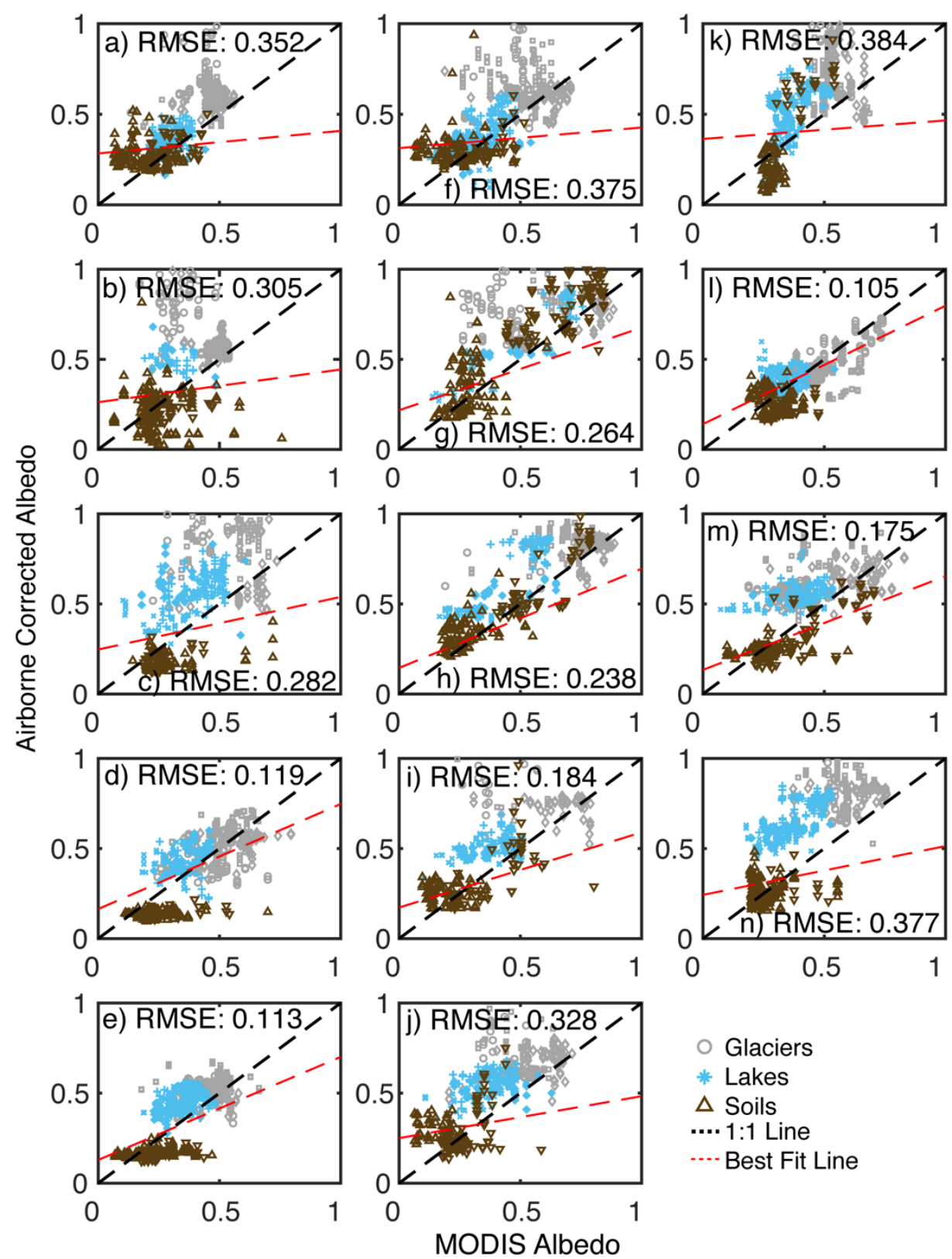

- Glaciers

* Lakes

$\Delta$ Soils

.... 1:1 Line

..--Best Fit Line

Figure S2: Comparison of corrected albedo to MODIS data across each flight in the (a-e) 2015-16 (f-j) 2016-17 and (k-n) 2017-18 seasons. 